This is a peer-reviewed, accepted author manuscript of the following conference paper: Wang, X., Dev, A. K., Tao, L., Chia, D. W., \& Zhang, Y. (2019). Slamming force contribution due to plunging breakers on circular, square and diamond cylinders. In ASME 2019 38th International Conference on Ocean, Offshore and Arctic Engineering: Volume 1: Offshore Technology; Offshore Geotechnics New York: American Society of Mechanical Engineers (ASME). https://doi.org/10.1115/OMAE2019-95126

OMAE2019-95126

\title{
SLAMMING FORCE CONTRIBUTION DUE TO PLUNGING BREAKERS ON CIRCULAR, SQUARE AND DIAMOND CYLINDERS
}

\author{
Xin Wang ${ }^{1}$, Arun $\mathrm{Kr}$ Dev \\ Faculty of Science, Agriculture and Engineering \\ Newcastle University, Newcastle upon Tyne, United \\ Kingdom
}

\author{
Longbin Tao \\ Naval Architecture, Ocean and Marine \\ Engineering University of Strathclyde, Glasgow, \\ United Kingdom
}

\author{
De Wang Chia ${ }^{2}$, Yali Zhang ${ }^{3}$ \\ Lloyd's Register Singapore Pte Ltd \\ Singapore
}

\section{ABSTRACT}

Plunging breakers, unlike non-breaking waves, impose additional slamming load on the offshore structures. This additional slamming load is considered an extreme event and is one of the most devastating forces that an offshore structure could encounter during its operational lifecycle.

Whilst there are design guidelines for offshore structures pertaining to breaking waves, however it is limited to only cylindrical shape. The amount of slamming load contribution by the plunging jet is also dependent on the cross section geometries of the offshore structures. Different geometries would give rise to different air entrainment phenomenon during wave breaking and therefore affecting the slamming load contributions.

In this research, JONSWAP spectrum was used to create plunging breakers via the focusing method at Newcastle University's Wind Wave and Current tank. The crux of this research is to investigate the wave-breaking impact load on cylindrical structures with different cross section geometries commonly used in the offshore industry.

Keywords: Plunging waves, Slamming load, Breaking waves

\section{INTRODUCTION}

Wave forces affecting offshore structures are of great interest for offshore industry. While being able to operate safely in desired sea condition is compulsory, having an overly conservative design formula could take a toll on the cost of designing and construction of an offshore structure.

For a slender body $(D<0.2 \lambda)$, diffraction effects could be neglected. Hence, wave force acting on a slender offshore structure could be approximated by the Morison equation [1]. This consisted of two forces; drag force and the inertia force.

$$
\begin{gathered}
F_{\text {total }}=F_{D}+F_{I} \\
F_{D}=0.5 * \rho_{w} * C_{D} * A * u *|u|
\end{gathered}
$$

$A=$ Reference area perpendicular to the wave propagation direction, in this case, $A=H_{\mathrm{b}} * D$

$$
F_{I}=\int_{-d}^{\zeta_{b}} C_{M} * \rho_{w} * \frac{\pi * D^{2}}{4} * \frac{\partial u(z)}{\partial t} * d z
$$

The inertia force is dependent on the acceleration of the horizontal water particles multiplied by the mass of displacement; none other than mass multiplied by acceleration.

For a lower Keulegan-Carpenter number, the inertia force forms the bulk of the force contribution, and vice versa for the higher Keulegan-Carpenter number. On the other hand, the drag coefficient and inertia coefficients are affected by the geometry of the structure, surface roughness etc.

\footnotetext{
${ }^{1}$ Contact author: xin.wang@ncl.ac.uk

${ }^{2}$ Final Year PhD student at Newcastle University

${ }^{3}$ Currently affiliated with Technology Centre for Offshore and Marine, Singapore
} 
The above Morison equation is inadequate to be applied for highly non-linear wave, especially plunging breakers. Plunging breakers induces an additional slamming load over a relatively short period of time.

SPM [2] stated for the design purpose, the contributing wave impact force could be 2.5 times the drag force. Goda [3] introduced an additional force term to be added to the original Morison equation to account for the additional slamming load induced by the plunging breaker.

$$
\begin{gathered}
F_{\text {total }}=F_{D}+F_{I}+F_{S} \\
F_{S}=0.5 * \rho_{w} * C_{s} * D * C_{b}^{2} * \lambda_{C} * \zeta_{b}
\end{gathered}
$$

$\lambda_{C}$ is the curling factor; a ratio of breaking wave impact length on structure over the breaking wave height. Von Karman [4] did an experimental study of maximum slamming impact of seaplane floats, and determined a slamming load equivalent of $2 \pi$. Wagner [5] expanded von Karman's [4] theory to consider the shape deformation of the water while in contact with the cylinder structure. Wagner noted a pile-up deformation effect after taking into consideration the rise of the free surface level, increasing the consideration of the wetted surface area. Therefore Wagner [5] recommends a slamming coefficient double the value of von Karman [4].

Blackmore and Hewson [6] installed wave pressure transducer at beach seawalls at differing locations in England. It was concluded that the rise time would have a negative correlation with the resulting impact pressure. A larger rise time would entrain larger amount of air and this would result in a lower slamming pressure. Chan and Melville [7] created breaking wave via focusing wave using the 'constant steepness' method. Pressure gauges were installed at the vertical wall along the elevation of wave impact. Chan and Melville [7] also observed the negative correlation between the rise time and the slamming pressure. Experiments were run repeatedly with the vertical wall placed at varying location to observe the critical wall position where the pressure maxima occurred.

It is observed that the critical wall distance is at the spatial distance whereby the plunging wave jet wasn't well formed. There would have a low initial air entrainment from the poorly formed jet before impact. However, if the vertical wall were to be placed further downstream, it would allow the plunging jet to be more matured and would result in a lower slamming pressure contribution as compared to the immature jet.

Some researchers [8,9] started to expand Wagner's [5] theory by introducing the slamming coefficient as a function of time; with the initial slamming coefficient peaking upon contact. Fabula [8] uses an ellipse fitting method to calculate the increased wetter surface area due to the deformation of the water, of 'pile-up effects'. Fabula [8] concluded his findings with the slamming coefficient peaking at $2 \pi$ upon initial contact and decaying rapidly. Cointe and Armand [9] describes the wetted cylinder boundary as a parabolic shape, and as compared to Fabula [8], Cointe and Armand [9] concluded a more gradual decaying phenomenon.

Wienke and Oumeraci [10] did experimental work on the breaking wave impact force. Pressure gauges were placed on different elevations of the cylinder and also along the circumference of the cylinder. Force transducers were placed on both ends of the cylinder to capture the total reaction force. The deformation of the water while in contact with the cylinder (pile-up effects), were taken into consideration for their experimental study.

Wienke and Oumeraci [10] derived slamming coefficient is time variable, with the initial maximum slamming coefficient of $2 \pi$, and then decaying with in agreement with Cointe and Armand [9] albeit with a steeper decaying towards the latter part of the slamming impact.

Wienke and Oumeraci [10] created a breaking wave focal point after the cylinder spatial location, to capture only the quasi-static loading acting on the cylinder and subtract the obtained quasi-static loading to other loading condition which involved plunging wave slamming jet loads; to obtain the contributing slamming loads. Next, using the obtained pressure values, they analyse the slamming pressure spreading along the circumference of the cylinder.

Slamming force could also be expressed as,

$$
F=\int_{z=-d}^{z=\zeta_{b}} f \cdot d z=f \cdot \lambda_{C} \cdot \zeta_{b}
$$

$\lambda_{C} \cdot \zeta_{b}=$ height of the plunging wave impacting the structure.

$f=$ slamming force per unit height

The curling factor $\left(\lambda_{C}\right.$, expressed as a ratio of less than 1) is being used to describe the ratio of the breaking wave height impacting the structure over the entire breaking wave height. The derived maximum curling factor Wienke and Oumeraci [10] achieved was consistent with Goda's [3] description of a typical curling factor value of 0.4 to 0.5 .

Chan and Melville [7] create plunging breakers of varying spatial focal point to plunge on a vertical wall. Chan and Melville [7] relate the slamming load according to the amount of air entrapment during breaking wave impact. The purpose of this paper is to expand the slamming coefficient to consider the effects of structural geometries. Different structure geometries would have different air entrapment properties and this would have a direct impact on the slamming load contribution.

\section{NOMENCLATURE}

$\begin{array}{ll}C_{A} & \text { added mass coefficient } \\ C_{b} & \text { phase celerity of breaking wave } \\ C_{D} & \text { drag coefficient } \\ C_{M} & \text { inertia coefficient } \\ C_{S} & \text { slamming coefficient } \\ C_{W} & \text { waterplane area coefficient } \\ d & \text { water depth }\end{array}$




$\begin{array}{ll}D & \text { diameter } \\ f_{\mathrm{P}} & \text { peak wave frequency } \\ F_{D} & \text { drag force } \\ F_{I} & \text { inertia force } \\ F_{S} & \text { slamming force } \\ F_{\text {total }} & \text { total force } \\ g & \text { gravitational acceleration } \\ H_{\mathrm{b}} & \text { height of breaking wave } \\ k & \text { wave number } \\ K C & \text { keulegan-carpenter number } \\ \lambda & \text { wavelength } \\ \lambda_{C} & \text { curling factor } \\ \zeta & \text { surface elevation } \\ \zeta_{a} & \text { wave amplitude } \\ \zeta_{\max } & \text { maximum surface elevation } \\ P_{W} & \text { water density } \\ P & \text { slamming pressure } \\ S_{J} & \text { JONSWAP spectrum } \\ T & \text { wave period } \\ t_{\mathrm{i}} & \text { rise time } \\ u & \text { horizontal wave particle velocity } \\ \omega & \text { wave angular frequency } \\ \omega_{P} & \text { peak wave angular frequency } \\ \gamma^{F} & \text { peak enhancement factor } \\ & \end{array}$

\section{EXPERIMENT METHODOLOGY}

\subsection{Experimental Set up}

\section{Equipment used}

a) 2 "GoPro Hero 6" cameras with recording frequency of 240fps. These 2 cameras were placed at the side of the Wind Wave and Current tank, overseeing the profile view of the breaking waves.

b) 1 Sony RV100 camera with recording frequency of 1000fps. This camera is used for the recording of the wave splash up. This splash up phenomenon could be as short as $40 \mathrm{~ms}$. Hence having a high speed camera would be beneficial.

c) 2 Acoustic Doppler Velocimeter (ADV) having a recording frequency of 200fps.

d) Cylinders with 3 different cross sections, discussed in details below

e) Force transducer with a recording capacity of $250 \mathrm{~N}$ in each 3 axial directions, with a recording frequency os 200fps.

f) 3 wave probes with recording frequency of $200 \mathrm{fps}$.

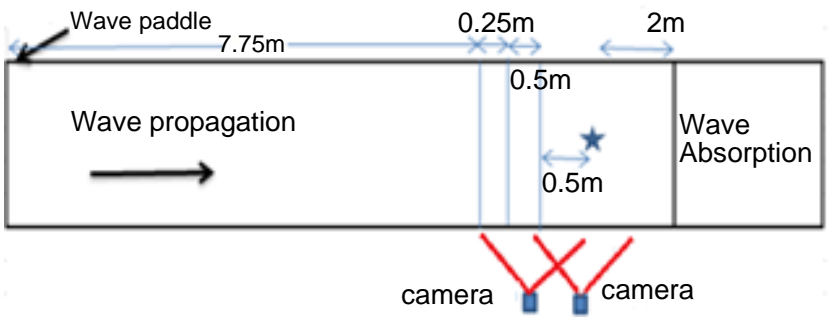

FIGURE 1. PLAN VIEW LAYOUT OF WAVE TANK, CYLINDER WILL BE PLACED AT $X=8.25 \mathrm{M}$, SQUARE DENOTES GOPRO 6 CAMERAS, WAVE PROBES DENOTED BY THE BLUE TRANSVERSE LINES AT X= 7.75M, 8M, AND 8.25M

This experiment was conducted at Newcastle University, in the Wind, Wave and Current Tank, having a dimension of $11 \mathrm{~m}, 1.8 \mathrm{~m}$, and $2 \mathrm{~m}$, length, width and height respectively. Water depth of $1 \mathrm{~m}$ was used, assuming deep-water relation $(d / \lambda>0.5)$. JONSWAP spectrum was used for this experimental work. The frequency range chosen was $0.25 \mathrm{~Hz}$ to $2 \mathrm{~Hz}$.

The focal point was chosen to be, $x_{\mathrm{B}}=9 \mathrm{~m}$, with an adjustable peak frequency ranging from $0.47 \mathrm{~Hz} \leq f_{\mathrm{P}} \leq 0.5 \mathrm{~Hz}$ for adjustment of the intensity of plunging breakers.

\section{Calibration of ADV positioning}

There were concerns for the placement of ADVs causing a potential disturbance to the force transducer measurements.

Assuming a 2-dimensional propagating wave, the y-axis placement of the ADVs could induce a fluid structure interaction (FSI) and creating rebounding wave effect and affecting the actual breaking wave impact loading and velocity profile reading.

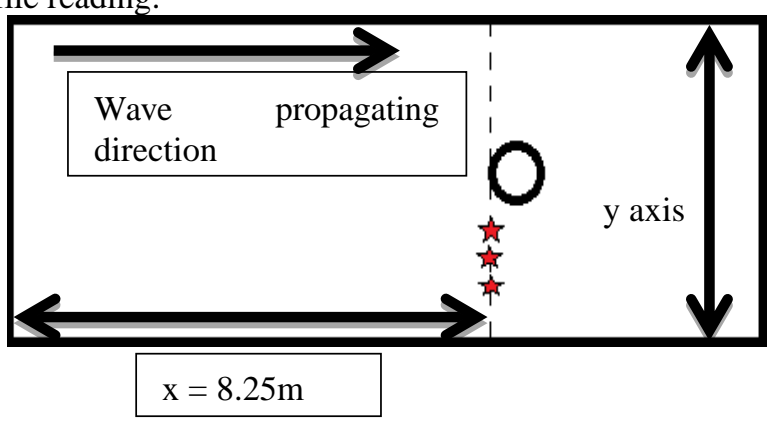

FIGURE 2. PLACEMENT OF ADVS AS DENOTED BY RED STARS

The cylinder would be placed at $\mathrm{x}=8.25 \mathrm{~m}$, and the ADV would also be placed at the same parallel $\mathrm{x}$-axis, albeit with varying y-axial placements (Fig. 2)

The ADV would be placed at $y=-0.5 \mathrm{~m}$ away from the cylinder, and be allowed to run 10 times. Subsequently, the ADV would be offset to differing $y$-axial location, $y=-0.2 m$, $0.3 \mathrm{~m}$. The mean and variance of the maximum resultant force resulting from the 3 different $y$-axial placements of the ADVs would be compared with the results of the default case. 
The velocity time history recordings of the ADVs would also be compared amongst the 3 different case studies. This is to gauge if there are much kinematics deviation with respect to further offset placement of the ADV. For the kinematics study, the ADV that was placed furthest from the cylinder; $y=-0.5 \mathrm{~m}$ in this case, would be the basis of comparative study.

The experiment case with ADV was run a total of 20 times using JONSWAP spectrum, with a peak frequency of $0.5 \mathrm{~Hz}$ and a gain factor of 1.2 . The $200 \mathrm{~mm}$ diameter cylinder was used and yielded an average peak inline force of $68.76 \mathrm{~N}$, with a low standard deviation of $0.336 \mathrm{~N}$ and a variance of $0.112 \mathrm{~N}$.

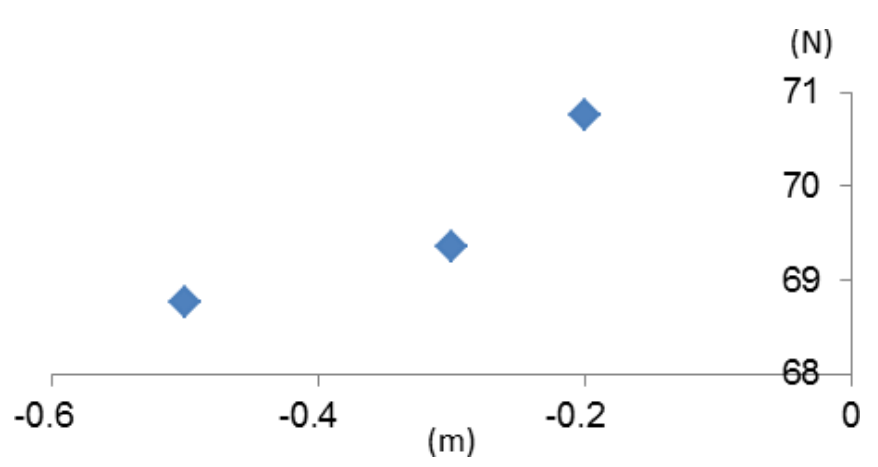

\section{FIGURE 3. AVERAGE PEAK FORCE FOR DIFFERENT SPATIAL LOCATION OF ADV AS INDICATED AT FIG. 2}

Fig. 3 seems to indicate that the peak force does get affected by the placement of the ADV. The closer the ADV is placed to the cylinder, the higher the average peak force is. The average peak force when the ADV is the closest to the cylinder; at a $0.2 \mathrm{~m}$ shift from the transverse axis, was $70.76 \mathrm{~N}$, a $3 \%$ increase as compared to the reading measured when the ADV was placed $0.5 \mathrm{~m}$ away from the cylinder. This seems to hint that the introduction of ADV might create some fluid structure interactions that would have a direct interference with the resultant force.

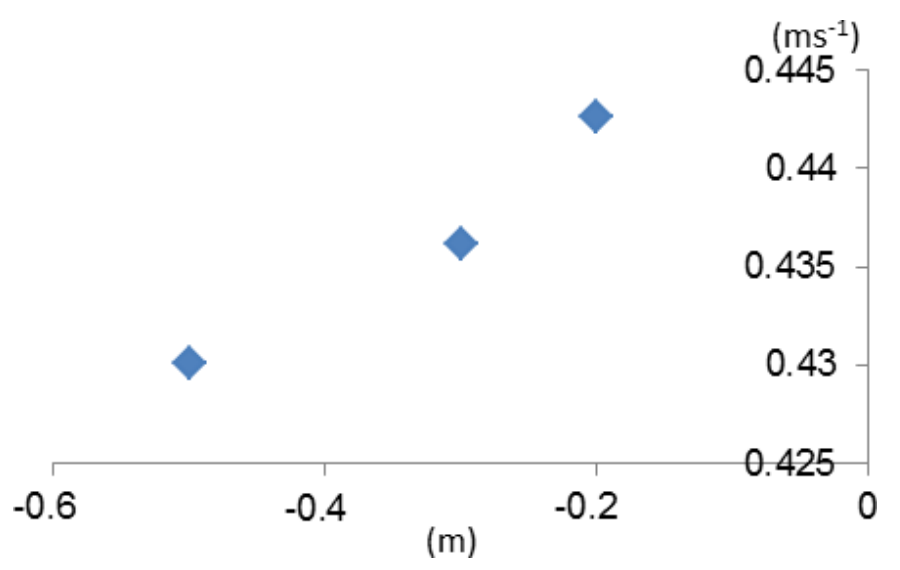

FIGURE 4. AVERAGE PEAK VELOCITY FOR DIFFERENT SPATIAL LOCATION OF ADV AS INDICATED AT FIG. 2

Fig. 4 shows similar phenomenon as Fig. 3, seeming to agree that the average peak velocity also experienced a marginal increment for ADVs that were placed closer to the cylinder. The average peak velocity at $0.2 \mathrm{~m}$ away from the cylinder was $0.443 \mathrm{~m} / \mathrm{s}$, a $3 \%$ increase over the achieved kinematics when the ADV was placed $0.5 \mathrm{~m}$ away.

In this research, 3 different types of cross sectional cylinders (circular cylinder, square cylinder and diamond cylinder) would be used for this experimental work. Circular cylinders with diameter of $200 \mathrm{~mm}$ (Fig. 5), 315mm, and $400 \mathrm{~mm}$ were used for the experiment.
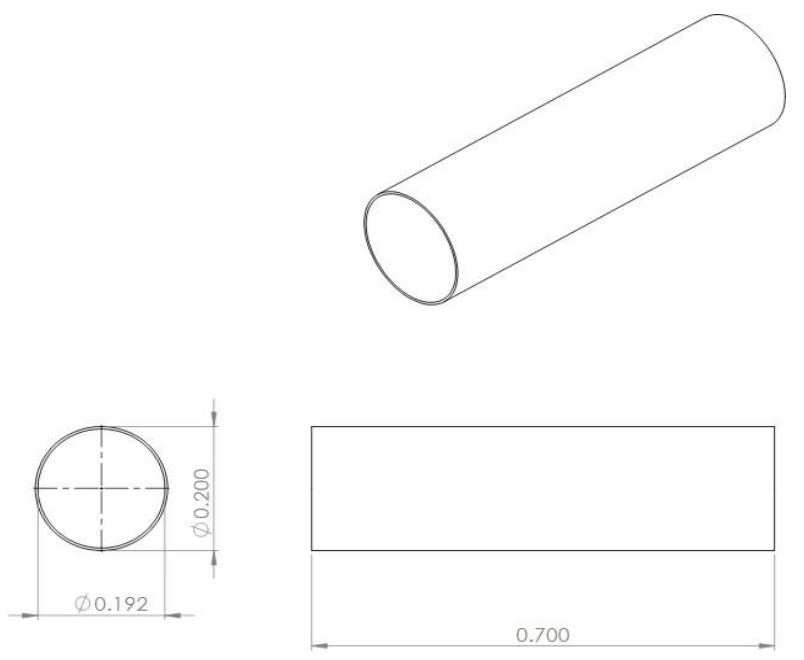

FIGURE 5. ENGINEERING DRAWING OF 200MM DIAMETER CIRCULAR CYLINDER

A square cylinder with an aspect ratio of 0.1 (filleted diameter over plate width) and a width of $200 \mathrm{~mm}$ were used. 


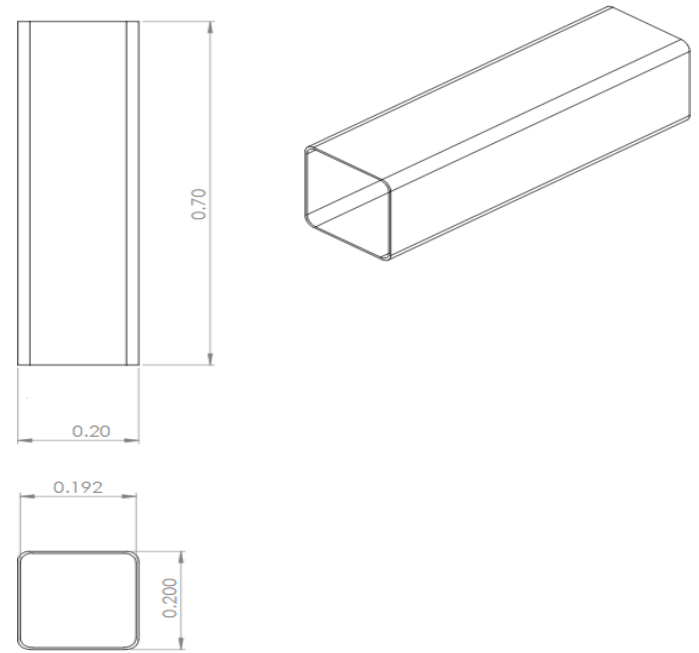

FIGURE 6. ENGINEERING DRAWING OF SQUARE CYLINDER

Twisting the above structure (Fig. 6) by 45 degrees along the vertical axis would portray as a diamond shaped cylinder, yielding a total of 5 cylinder cases.

\subsection{Wave Parameters}

JONSWAP spectrum was used for creating focused wave; plunging breakers in this experiment. (Eq. 7)

$$
S_{j}(\omega)=\frac{\alpha * g^{2}}{\omega^{5}} * \exp \left[-1.25 *\left(\frac{\omega_{D}}{\omega}\right)^{4}\right] * \gamma^{r}
$$

The peak angular frequency $\left(\omega_{p}\right)$ was adjusted to create different intensities of breaking wave. A lower $\omega_{\mathrm{p}}\left(\right.$ or $\left.f_{\mathrm{P}}\right)$ will give a stronger plunging breaker.

\section{Assumptions for Morison's equation}

The diameter $(D)$ of the cylinder and the characteristic wavelength $(\lambda)$ should be $D / \lambda<0.2$

The wavelength of the incoming propagating wave was estimated via wave probe. Ying $\mathrm{Tu}$ et al [11] estimated the wavelength by using the zero-crossing analysis method. It was known that the use of capacitance type wave probes were prone to white noises. And also assuming that the spatial evolution of the propagating wavelength could be approximated from the temporary evolution, the wavelength could be estimated.

The wave probe readings were first post-processed to eliminate any non-zero mean surface elevation. Next, the elevation readings on the wave probe were smoothed using a 1second moving average to remove any white noises. The obtained zero-crossing period were then extracted from this data and be used to estimate the wavelength of the breaking wave.
TABLE 1: Wave Parameters

\begin{tabular}{|r|r|r|r|}
\hline \multicolumn{1}{|r|}{$f_{\mathrm{p}}$} & \multicolumn{1}{|l|}{$T_{\mathrm{z}}$} & \multicolumn{1}{l|}{} & \multicolumn{1}{l|}{$\mathrm{D} / \Lambda$} \\
\hline 0.47 & 1.096 & 1.875 & 0.107 \\
\hline 0.48 & 1.080 & 1.821 & 0.109 \\
\hline 0.49 & 1.062 & 1.760 & 0.114 \\
\hline 0.5 & 1.025 & 1.641 & 0.122 \\
\hline
\end{tabular}

30 readings each were taken for the analytic of the wave parameters. The wavelength is calculated using the averaged of the zero-crossing period analysis. The $(D / \lambda)$ is computed using a diameter of $0.2 \mathrm{~m}$. The above table shows that stronger wave breaking intensities (or lower peak frequency), would create lengthier wavelength before breaking.

For this experiment, cylinder diameters ranging from $200 \mathrm{~mm}$ to $400 \mathrm{~mm}$ were used. This would have meant that the research work revolves having $(D / \lambda)$ ratio of 0.106 to 0.244 .

Regular waves were constructed and the time history of the wave kinematics was recorded using the ADV with a recording frequency of $200 \mathrm{~Hz}$. The force transducer is mounted at the top of the cylinder and allows the cylinder to be on a fixed-free position. The waves are propagated in a $2 \mathrm{D}$ direction. Even though tri-directional wave kinematics and forces were recorded in the experiment, however y-axial kinematics and forces are negligible.

\section{POST PROCESSING}

$$
\frac{\partial u}{\partial t}=\zeta_{a} * g * k * \frac{\cosh k(z+i h)}{\sinh (k * h)} * \sin (k x-\omega t)
$$

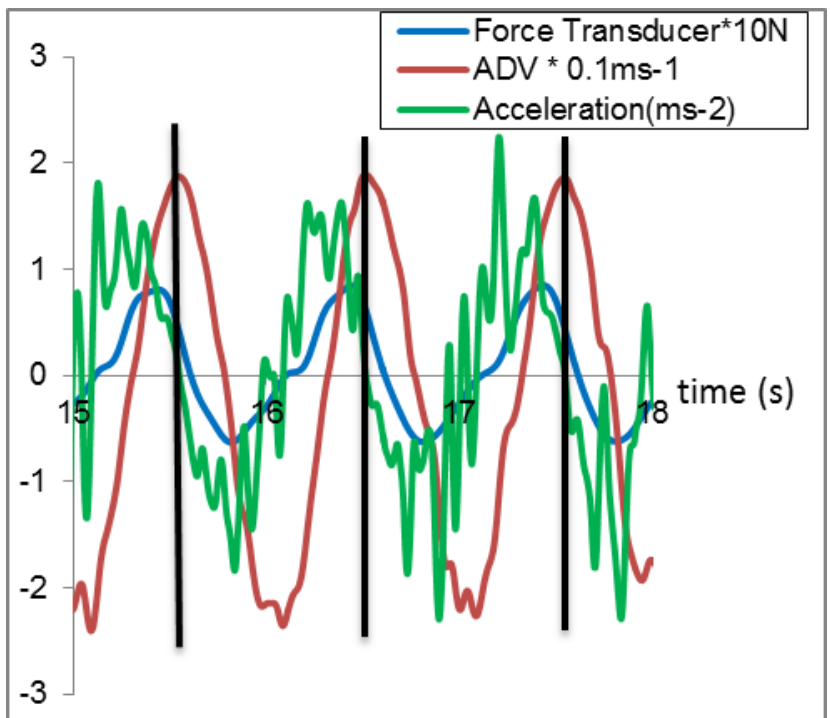

FIGURE 7. WAVE KINEMATICS AND INDUCED FORCE TIME HISTORY AT $Z=-80 M M$, REGULAR WAVE CASE, $T=1$ SECOND. WAVE AMPLITUDE = 40MM 
Fig. 7 shows the reading of wave horizontal particle velocity time history recorded by the ADV, and also the recorded force time history. The acceleration time history was extracted using Eq. 8. As shown in Fig. 7, a vertical line was constructed at each time step when maximum velocity was registered. The wave kinematics registered the lowest sample variance of $4.192 \times 10^{-5} \mathrm{~m} / \mathrm{s}$ when the ADV was placed at lower elevation, $\mathrm{z}=-80 \mathrm{~mm}$ with a mean velocity of $0.186 \mathrm{~m} / \mathrm{s}$, and the highest velocity sample variance of $1.9 \times 10^{-3} \mathrm{~m} / \mathrm{s}$ at the higher elevation, $z=40 \mathrm{~mm}$ with a mean velocity of $0.337 \mathrm{~m} / \mathrm{s}$. The variance-to-mean ratio (VMR) for the recorded wave kinematics were only $0.57 \%$ when $\mathrm{z}=40 \mathrm{~mm}$, giving a relatively constant output.

On above Fig. 7, the vertical line that passes through the force time history, is assumed to be of purely only drag force (Eq. 1, Eq. 2, Eq. 3) due to negligible acceleration. Applying Eq. 2, and using the average of the obtained associated drag force contribution and horizontal wave particle velocity, the drag coefficient could be approximated.

For each of the wave signals, at least 10 sets of peak wave force values, drag force and their associated wave kinematics (velocity), inertia force and their associated wave kinematics (acceleration) were recorded and analysed. These values were recorded after the first few waves; to minimize influence of the evanescent wave generated by the wavemakers.

Each wave signals were allowed to run with the ADVs being placed at 10 different elevations to capture the associated wave kinematics. And each elevation, the experiment is run 10 times to obtain a larger set of data and lowering the sampling variance.

According to DNV rulebook [12], the value of the drag coefficient is affected by the surface roughness and KeuleganCarpenter number.

$C_{D}=C_{D S}(\Delta) * \Psi(K C)$

$C_{D S}(\Delta)$ assumed to be 0.65 for smooth cylinder.

$\boldsymbol{\Psi}=$ wake amplification factor

$$
K C=\pi * \frac{H}{D}
$$

Where $K C$ is the Keulegan Carpenter formula to be used for structure in wave zone.

$$
\begin{array}{ll}
H=\text { wave height }(\mathrm{m}), D=\operatorname{Diameter}(\mathrm{m}), \\
\boldsymbol{\Psi}=1.3+0.1(K C-12) & 2<K C<12 \\
\boldsymbol{\Psi}=0.3 & 0.75<K C<2 \\
\boldsymbol{\Psi}=0.3-2(K C-0.75) & K C \leq 0.75
\end{array}
$$

For this regular wave case, the ADV was placed at 5 differing surface elevation, yielding velocity reading ranging $0.2 \mathrm{~m} / \mathrm{s}$ to $0.6 \mathrm{~m} / \mathrm{s}$. Through earlier obtained drag coefficient, and obtained wake amplification factor for differ surface elevation, $C_{D S}(\Delta)$ could be established. In the breaking wave case, the obtained $C_{D S}(\Delta)$ value could be reused and multiply by the contributing wake amplification factor to estimate the final drag coefficient contribution.

The above step was repeated, and plotted when velocity is negligible; when acceleration is at the maximum, neglecting the drag forces component. Applying Eq. 3, the mass coefficient could be approximated.

The obtained drag and mass coefficient are then cross verified with the average maximum force incurred by the regular wave force.

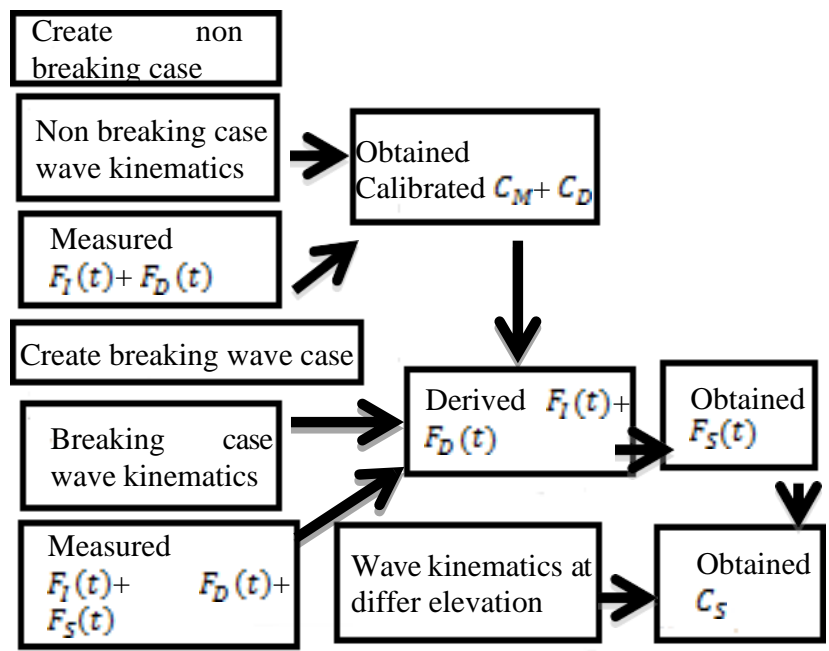

FIGURE 8. WORK FLOW TO DETERMINE SLAMMING LOAD COEFFICIENT

As explained in above Fig. 8, regular waves were created to obtain the non breaking coefficients; added mass and drag coefficients.

In the irregular wave case that involves breaking wave, there are slamming load components together with the drag and inertia components. Using the experimentally obtained added mass and drag coefficients in the non-breaking wave case, and with the recorded wave kinematics, the contributed inertia and drag force component would be estimated (Eq. 2, Eq. 3). Finally, the slamming load contribution could be derived from subtracting the drag and inertia component (Eq. 4).

\section{RESULTS AND DISCUSSIONS}

As shown in previous Fig. 7, the drag force values were extracted when acceleration is zero (when inertia force is negligible). 


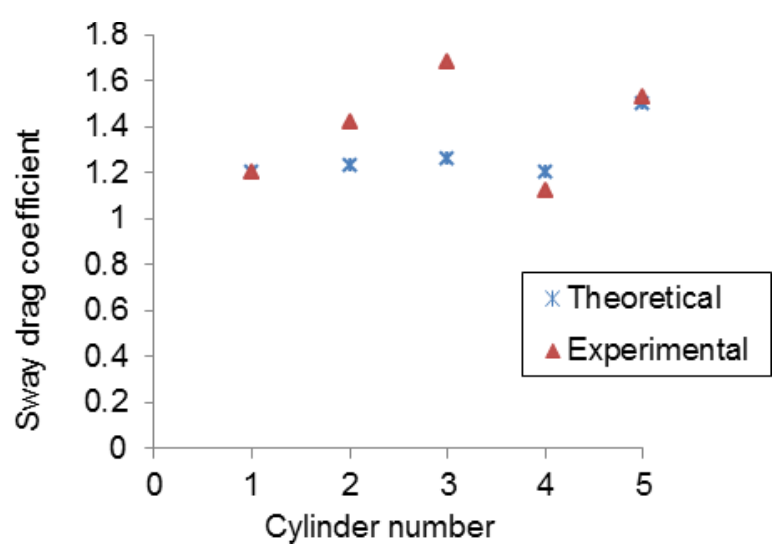

FIGURE 9. SWAY DRAG COEFFICIENT FOR DIFFERENT CYLINDERS (1- 200MM CIRCULAR CYLINDER, 2- 315MM CIRCULAR CYLINDER, 3400MM CIRCULAR CYLINDER, 4-SQUARE CYLINDER, 5- DIAMOND CYLINDER)

Fig. 9 showed the 5 cylinders sway hydrodynamic coefficient values derived from experimental works and from DNV rulebook [12,13]. Comparing the first 3 cylindrical cases, it seemed to hint at a larger boundary wall effects as compared to the theoretical values obtained from DNV. The experimental drag coefficient obtained had a good agreement with the class rules.

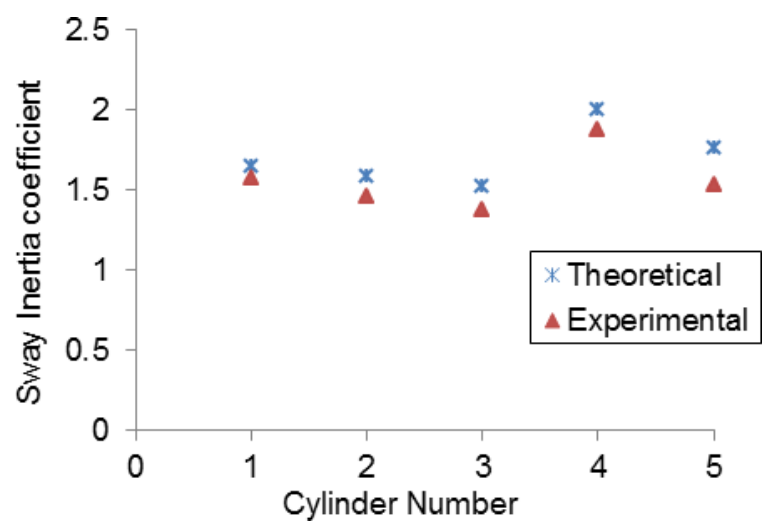

FIGURE 10. SWAY INERTIA COEFFICIENT FOR DIFFERENT CYLINDERS (1- 200MM CIRCULAR CYLINDER, 2- 315MM CIRCULAR CYLINDER, 3400MM CIRCULAR CYLINDER, 4-SQUARE CYLINDER, 5- DIAMOND CYLINDER)

Tarik and Sander [14] investigated the inertia coefficient for vertical cylinder non-dimensional sizes amongst sway and heave responses. The impact on the coefficients were plotted as a function of different non-dimensional parameters;

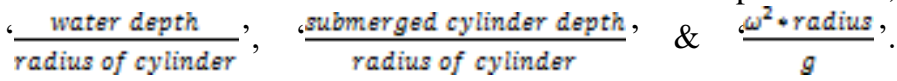
Taking $\left(C_{M}=1+C_{A}\right)$, the inertia coefficient is plotted amongst the theoretical and experimental values (Fig. 10). The theoretical value of cylinder $2(315 \mathrm{~mm}$ diameter cylinder) was estimated via the theoretical values of cylinder 1 and $3(200 \mathrm{~mm}$ \& $400 \mathrm{~mm}$ diameter cylinder). The non-circular inertia coefficient theoretical values were obtained from DNV [13]. Fig. 10 shows a good agreement between the theoretical and experimental values for the Sway inertia coefficient.

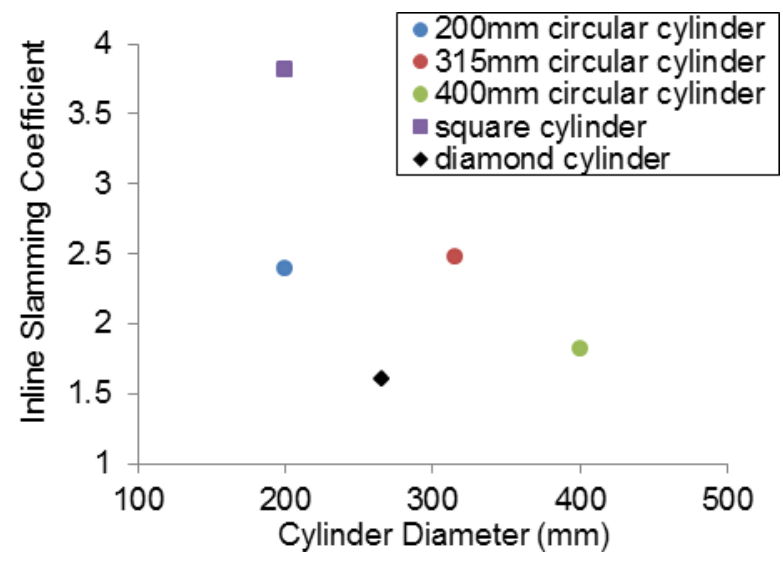

FIGURE 11. INLINE SLAMMING COEFFICIENT FOR CYLINDER WITH DIFFERENT GEOMETRIES CROSS SECTION AND CIRCULAR CYLINDER WITH DIFFERENT DIAMETER

Fig. 11 showed the inline slamming coefficient from the 5 different cylinders. It shows that geometry cross section of the structure plays a significant role in the inline slamming coefficient. However, slamming force isn't a 1-directional force. During the collapsing of the plunging jet, the jet was allowed to collapse with the assistance of gravitational force, and at that moment, the structure inevitably suffered downwards slamming force. Hence, the vertical axis contribution shouldn't be neglected as well. 


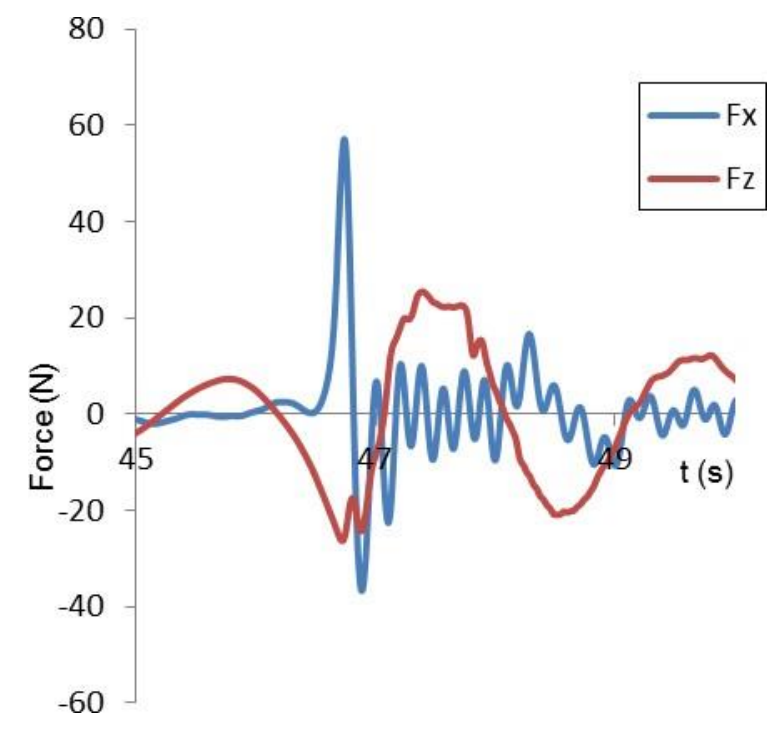

FIGURE 12. HORIZONTAL AND VERTICAL FORCE TIME HISTORY DURING ONSET OF PLUNGING JET, FOR 200MM CIRCULAR CYLINDER

During the onset of plunging breaker (Fig. 12), at $t=$ $46.75 \mathrm{~s}$, the inline force maxima coincides with the vertical force minima. This would relate to earlier discussion that slamming force induces a 2-dimensional force contribution (inline and downward force).

\section{Vertical contribution}

In the z-direction, the structure would encounter heave added mass force, and as well as lift force. This lift force could be a result from, unsymmetrical geometry, vortex shedding, wake effects or wall effects (structure being too near to the boundary). However in this experiment, lift force will only occur due to wall effects. The lift force due to unsymmetrical geometry is impossible as symmetrical structure were used in this experimental work. Wake effects induced lifting force isn't applicable as there wasn't a disturbed flow before breaking. And finally, in this experimental set up, operates at a maximum Reynolds Number of $\sim 7$; which shedding effects could be neglected; DNV RP-C205 [12] calls for a critical minimum Reynolds Number of 10, Kou et al. [15] concluded that the lowest Reynolds Number of VIV to be at 12 . There would be negligible wall induced lifting force for a gap ratio

$\left(\frac{\text { Gap between cylinder and wall }}{\text { cylinder diameter }}\right)>0.5$. Hence the lift force in this experimental work would be negligible.

According to Tarik and Sander [14], the theoretical heave added mass coefficient ranging from 1.05 to 1.35 for this experimental work.

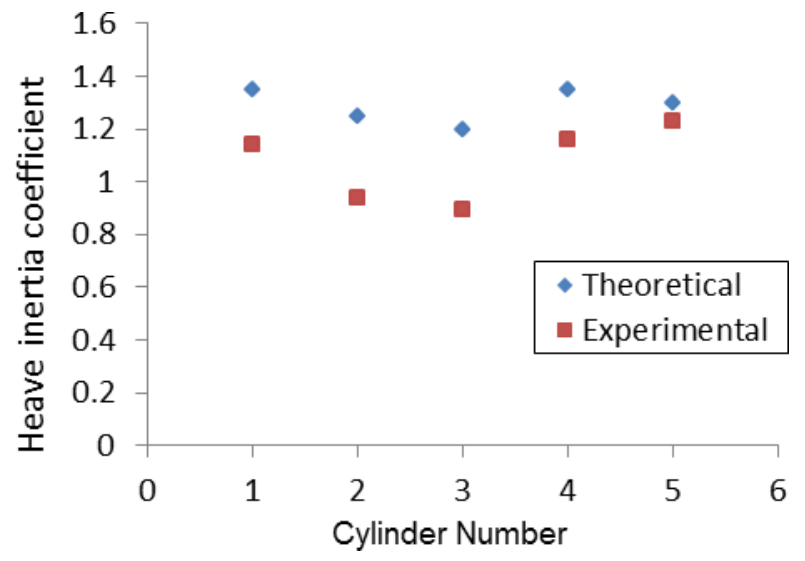

FIGURE 13. HEAVE INERTIA COEFFICIENT FOR DIFFERENT CYLINDERS (1- 200MM CIRCULAR CYLINDER, 2- 315MM CIRCULAR CYLINDER, 3400MM CIRCULAR CYLINDER, 4-SQUARE CYLINDER, 5- DIAMOND CYLINDER)

According to Fig. 13, the experimental yielded a slightly lower coefficient than the empirical values [14] and for calculation of the resultant slamming load contribution, the conservative heave added mass coefficient yielded from the experiment (Fig. 13) would be used

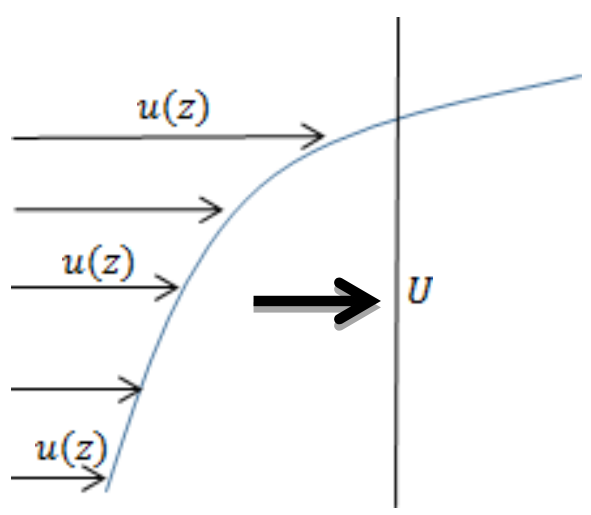

FIGURE 14. VELOCITY FIELD

The drag and slamming force are related to the associated squared velocity, and in turn, the wave kinematics profile is a function of the recording elevation (Fig. 15).

$$
\begin{aligned}
& U^{2}=\sum_{z=-0.1 m}^{z=0.2 m} \frac{w(z)^{2}}{N} \\
& W^{2}=\sum_{z=-0.1 m}^{z=0.2 m} \frac{w(z)^{2}}{W} \\
& N=\frac{z}{d z}
\end{aligned}
$$




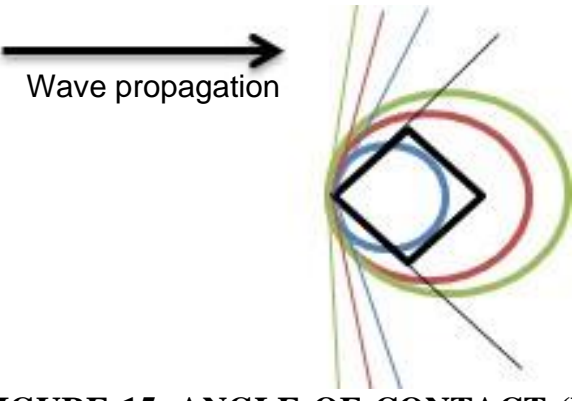

FIGURE 15. ANGLE OF CONTACT (DENOTED BY THE SPREAD OF COLOURED LINES) FOR CYLINDER WITH DIFFERENT GEOMETRIES CROSS SECTION AND CIRCULAR CYLINDER WITH DIFFERENT DIAMETER

Fig. 15 shows that the angle of contact amongst the 3 circular cylinders and the diamond cylinder. The larger diameter circular cylinder would have an angle of contact closer to 180 degree (denoted by green lines); almost equivalent to an angle of contact for a square cylinder. This means that for a large diameter circular cylinder, the slamming load phenomenon could be assumed to be similar to that of a flat plate wall; a square cylinder. On the other hand, the smaller diameter circular cylinder would have a larger angle of contact, however not as large as the angle of contact of a diamond cylinder; which explains the associated slamming load contribution.

Fig. $11 \& 15$ showed a negative correlation between the angle of contact and the associated slamming load contribution. During the onset of breaking, the plunging jet came into contact with the offshore structure, creating an interfacial aeration. This would create some air entrapped between the interfacial and the cylindrical wall.

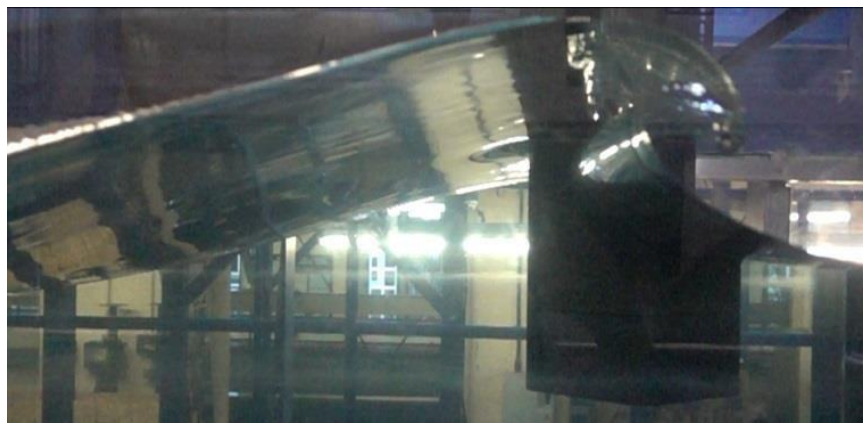

FIGURE 16. PLUNGING JET COLLAPSING ON A DIAMOND CYLINDER

The diamond cylinder having the largest angle of contact (Fig. 16), is shown to have a 'calmer' breaking impact amongst all the 5 cylinders.

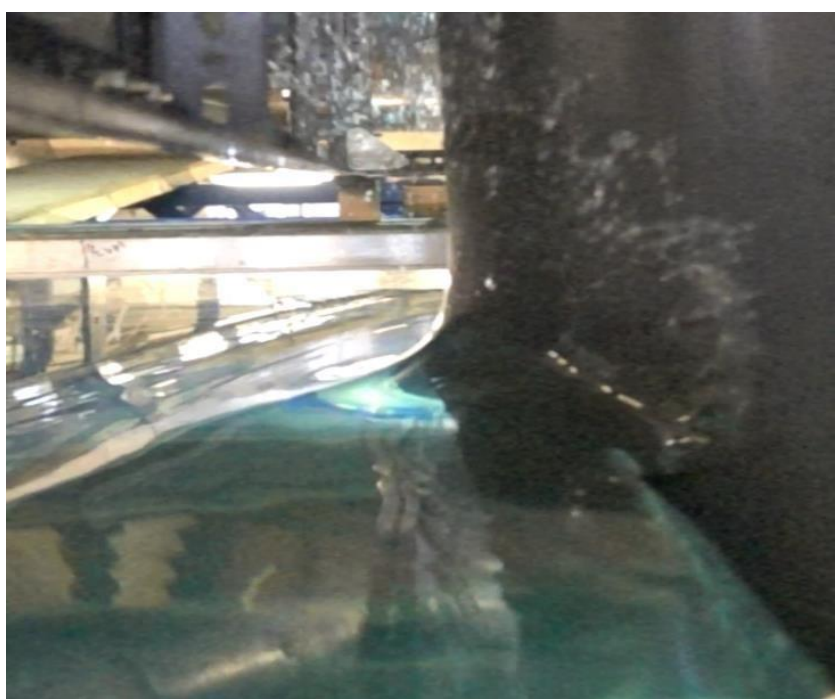

FIGURE 17. PLUNGING JET COLLAPSING ON A 400MM DIAMETER CIRCULAR CYLINDER

The behavior of the breaking wave impact loading on the $400 \mathrm{~mm}$ diameter (Fig. 17) is more violent than that of smaller circular diameter cylinders and the diamond cylinder. A lower angle of contact, allows for lesser avenues for the entrapped gas to escape during initial breaking jet contact, resulting in a higher slamming contribution.

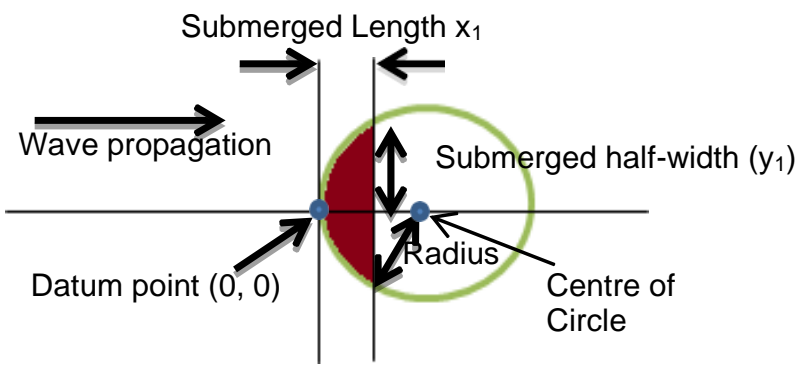

FIGURE 18. PROFILE VIEW OF CIRCULAR CYLINDER DURING INITIAL IMPACT (SHADED AREA DENOTES CONTACT AREA)

$$
\begin{aligned}
& x_{1}=t_{i} * C_{b} \\
& y_{1}^{2}=r^{2}-\left(r-x_{1}\right)^{2} \\
& y_{1}=\sqrt{2 * x_{1} * r-x_{1}^{2}}
\end{aligned}
$$

Fig. 18 shows the parameters involved in the estimation of the coefficient of waterplane area $\left(\frac{\text { shaded area }}{x_{1} * y_{1}}\right)$ upon onset of breaking wave. The contact area of the circular cylinders could be derived with the known values of $d y_{1}$ and $\mathrm{r}$ (cylinder radius)(Eq. 14, Eq. 15 and Eq. 16);

Submerged Length $x_{1}$ 


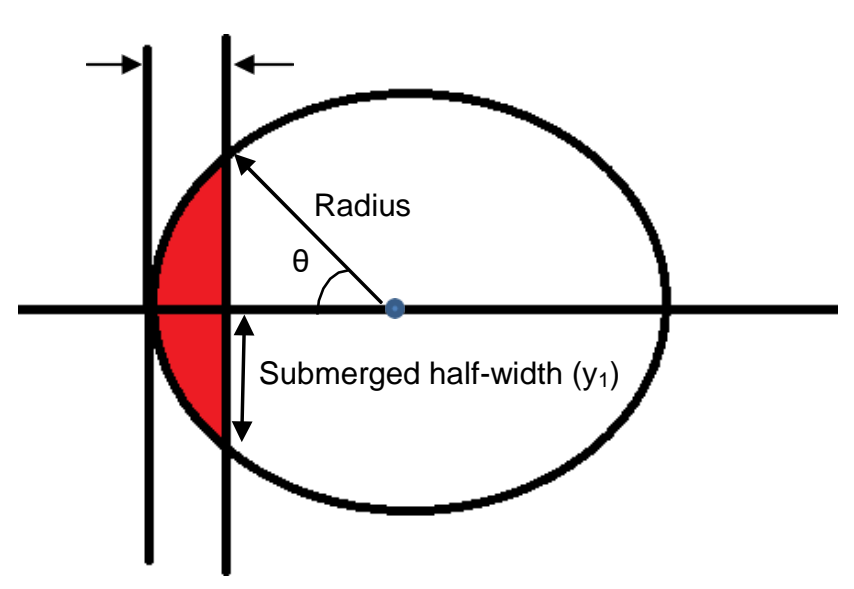

FIGURE 19. CALCULATION OF CONTACT AREA

$$
\theta=\sin ^{-1}\left(\frac{y_{1}}{r}\right)
$$

Area of sector $=\frac{2 \theta}{a 60} * \pi * r^{2}$

The area of the sector which covers the contact area and 2 isosceles triangles could be calculated using Eq. 17 and Eq. 18. The Contact area could then be derived via Eq. 18 by subtracting the area of 2 isosceles triangles.

$$
\text { Contact area }=\frac{2 \theta}{360} * \pi * r^{2}-2 * 0.5 * \mathrm{y}_{1} *\left(r-x_{1}\right)
$$

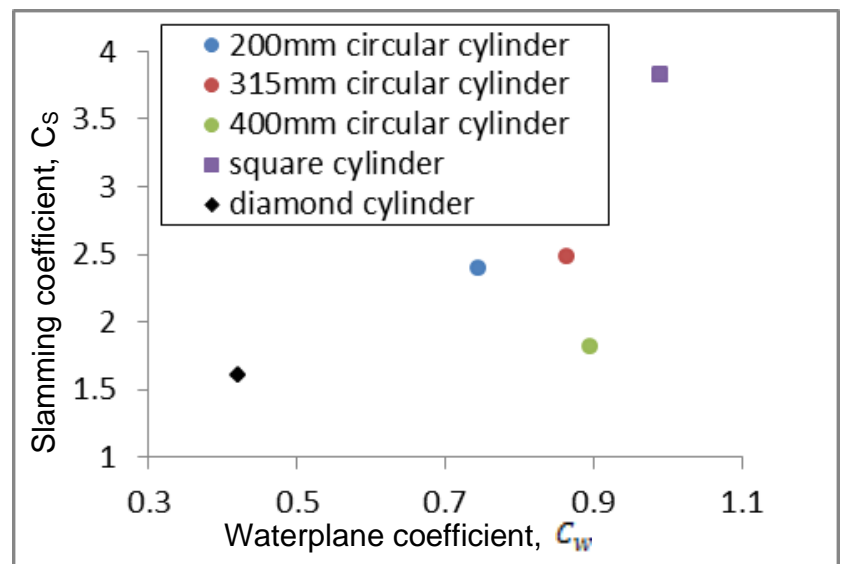

\section{FIGURE 20. SLAMMING LOAD CONTRIBUTION VS WATERPLANE COEFFICIENT}

Taking the reference plane area as, $0 m \leq x \leq x_{1}$, $0 m \leq y \leq y_{1}$ (Datum point shown on Fig. 18), the waterplane coefficient for the 5 cylinders are calculated and plotted against their contributory slamming load coefficient (Fig. 20).

The above figure gives an R-squared value of 0.5192. The value of the slamming coefficient for the $400 \mathrm{~mm}$ diameter circular cylinder might be affected by wave diffraction; due to having a $(D / \lambda)$ of 0.244 . Otherwise, it could be seen that the geometrical cross-section and the waterplane coefficient do have an inversely proportional relationship with the slamming load coefficient. A lower waterplane coefficient would be associated with more leeway for the otherwise entrapped gas to disperse, resulting in a lower slamming pressure and slamming load contribution.

\section{CONCLUSIONS AND RECOMMENDATIONS}

During the onset of breaking, the plunging jet creates an interfacial aeration between the collapsing jet and the structure. The magnitude of the slamming load is dependent on the air entrapment capability during the breaking. Different geometrical cross section structure would have differing air entrapment capability.

In this experimental work, 3 different geometrical cross section cylinders were used; the circular, square and diamond. It is found that the cylinders with different geometrical cross sections would have varying angle of contact and waterplane coefficient. This would have a direct impact on the air entrapment and also the associated slamming load contribution.

Whilst, there are industry design guidelines for designing an offshore structure against breaking wave [13], however the practice only considers circular cylinder. This experimental work shows that for the same wave breaking signal, a diamond cylinder would have a slamming coefficient less than half of that of a square cylinder. It would be beneficial to the industry if more experimental work could be done on the different crosssection geometries implications on the slamming coefficient and to recommend a semi-empirical formula based on the findings.

\section{ACKNOWLEDGEMENTS}

The research team would like to thank Singapore Economic Development Board and Lloyd's Register Singapore Pte Ltd for funding this experimental work. Special thanks to the Newcastle University Hydrodynamics Lab team for their kind support to make this experimental work possible.

\section{REFERENCES}

[1] Morison, J.R., O’Brien, M.P., Johnson, J.W., Schaaf, S.A., (1950) 'The forces exerted by surface waves on piles.' Journal of Petroleum Technology, Petroleum Transactions, AIME 189, pp 149 - 154

[2] Shore Protection Manual Vol 2. Coastal Engineering Research Center, Department of the Army.

[3] Goda, Y.,Haranaka,S., Kitahata, M., (1966). 'Study of impulsive Breaking Wave Forces on Piles. Report of Port and Harbor Research Institute, 5(6): 1-30

[4] von Karman, T., (1929) 'The impact on seaplane floats during landing.' National Advisory Committee for Aeronautics. Technical Note, vol. 321

[5] Wagner, H., (1932) Uber Stoss-und Gleitvorgange an der Oberflache von Flussigkeiten. Z. Angew. Math. Mech., 12, pp 193-215 
[6] P.A Blackmore., P.J. Hewson., (1984) 'Experiments on Full-Scale wave impact pressures' Coastal Engineering, 8 (1984) pp 331-346

[7] Chan E.S, W.K. Melville.,(1988) 'Deep-water plunging wave pressures on a vertical plane wall' 'Proc. R. Soc. Lond. A 417, 95-131 (1988)

[8] Fabula, A., 'Ellipse-Fitting Approximation of twodimensional Normal Symmetric Impact of Rigid Bodies on Water' Proceedings, Fifth Mid-western Conference on Fluid dynamics, University of Michigan Press, Ann Arbor, Mich, 1957

[9] R. Cointe, J.L. Armand., (1986) 'Hydrodynamic Impact Analysis of a Cylinder' Journal of Offshore Mechanics and Arctic Engineering, Vol. 109, pp 237-243

[10] J. Wienke, H. Oumeraci (2005) 'Breaking wave impact force on a vertical and inclined slender pile- theoretical and large-scale model investigations' Coastal Engineering 52 (2005) 435-462

[11] Ying Tu, Z.S. Cheng, Michael Muskulus, (2017) 'A review of slamming load application to offshore wind turbines from an integrated perspective' $14^{\text {th }}$ Deep Sea Offshore Wind $R \& D$ Conferences, Trondheim, Norway.

[12] Veritas, D.N., 2010. RP-C205 Environmental Conditions and Environmental Loads

[13] Veritas, D.N., 2011. RP-H103 Rules and standards

[14] Tarik Sabuncu., Sander Calisal., (1981) 'Hydrodynamic Coefficients for Vertical Circular Cylinders at Finite Depth' U.S. Naval Academy, Annapolis, MD,USA

[15] Jiaqing Kou, Weiwei Zhang, Yilang Liu, Xintao Li (2017) 'The lowest Reynolds number of vortex-induced vibrations' Physics of Fluids 29, 041701 (2017) 